\title{
Prognostic impact of PCR-based identification of isolated tumour cells in the peritoneal lavage fluid of gastric cancer patients who underwent a curative $\mathrm{RO}$ resection
}

\author{
K Katsuragi', M Yashiro*,', T Sawada', H Osaka', M Ohira' and K Hirakawa' \\ 'Department of Surgical Oncology, Osaka City University Graduate School of Medicine, I-4-3 Asahi-machi, Abeno-ku, Osaka 545-8585, Japan
}

Identification of cancer cells in the peritoneal cavity could influence therapy and outcome of gastric carcinoma patients. The objective of this study was to evaluate the clinical impact of the real-time quantitative polymerase chain reaction-(PCR) based identification of isolated tumour cells in the peritoneal lavage fluid of gastric carcinoma. The peritoneal lavage fluid of I I 6 patients with gastric cancer was sampled at laparotomy. After RNA extraction and reverse transcription, real-time quantitative PCR was performed using the primers and probes for carcinoembryonic antigen (CEA) and cytokeratin-20 (CK20). When either the CEA mRNA or CK20 mRNA level of the sample was over the cutoff value, the sample was determined to be PCR-positive. Forty-six (40\%) of the II6 patients were PCR-positive and 30 (65\%) of the 46 PCR-positive patients died as a result of recurrent peritoneal dissemination. The prognosis of the 46 PCR-positive patients was significantly $(P<0.001)$ worse than that of 70 PCR-negative patients. Furthermore, in 80 of the cases with a curative $\mathrm{R} 0$ resection, I 5 of the patients with $\mathrm{PCR}$-positive findings had a significantly $(P<0.00 \mathrm{I})$ poorer prognosis than the 65 PCR-negative patients. The prognosis of the PCR-positive patients was significantly poorer than that of the PCR-negative patients in the T3 $(P<0.000 \mathrm{I})$ and T4 $(P=0.048)$ subgroups. In a multivariate analysis of the 80 cases with a curative R0 resection, the real-time quantitative RT-PCR (CEA and/or CK20) levels indicated that they were independent prognostic factors. The real-time quantitative RT-PCR analysis of the CEA and/or CK20 transcripts in the peritoneal lavage fluid is useful for predicting the peritoneal recurrence in patients who are undergoing a curative resection for gastric cancer.

British Journal of Cancer (2007) 97, 550-556. doi: I0.1038/sj.bjc.6603909 www.bjcancer.com

Published online 3 I July 2007

(c) 2007 Cancer Research UK

Keywords: gastric cancer; micrometastasis; prognosis; peritoneal dissemination

The prognosis of patients with early gastric cancer has been improved in recent years. However, patients with an advanced form of gastric carcinoma, especially a serosa-invading tumour such as a T3 or T4 cancer, still have a poor prognosis (Martin et al, 2002; Tsuburaya et al, 2005). The detection of micrometastases and disseminated cancer cells in patients with tumours who are undergoing curative surgery is a challenging field in oncology because the dissemination of neoplastic cells is the main reason for distant relapse and cancer-related death (Timar et al, 2001). Peritoneal dissemination is the most common type of recurrence after surgery in these advanced cases and is one of the reasons for their poor prognosis (Baba et al, 1989; Yoo et al, 2000). Peritoneal dissemination may arise from the free cancer cells in the peritoneal cavity exfoliated mainly from the serosal surface of the primary tumour. Cancer identification of the tumour cells in the peritoneal cavity could influence the therapy and the outcome of the patients undergoing surgery for advanced gastric carcinoma.

Peritoneal lavage cytology at laparotomy has been a standard method for the detection of free tumour cells and a useful predictor of peritoneal recurrence in gastric cancer. However, by the conventional cytology, patients with negative cancer cells have occasionally developed recurrent peritoneal disease after surgery,

*Correspondence: Dr M Yashiro; E-mail: m9312510@med.osaka-cu.ac.jp Received 12 April 2007; revised 29 June 2007; accepted 29 June 2007; published online 31 July 2007 which thus resulted in a low sensitivity of the cytology (Boku et al, 1990; Abe et al, 1995; Schofield et al, 1997; de Manzoni et al, 2006). Almost half of all patients with serosa-invading gastric carcinoma experience peritoneal recurrence even after a curative surgical resection (Martin et al, 2002; Tsuburaya et al, 2005). These patients with recurrent peritoneal disease have already developed micrometastasis on the peritoneum at the time of surgery. Micrometastases are defined as single disseminated tumour cells or small clusters of neoplastic cells, which can be occasionally detected by conventional cytology (Singletary et al, 2003; Sobin, 2003). Recently, the reverse transcriptase-polymerase chain reaction (RT-PCR) technique has made it possible to detect only a few cancer cells in the abdominal cavity and the technique is more sensitive than with traditional peritoneal lavage cytology (Kodera et al, 1998; Timar et al, 2002). The conventional RT - PCR used for the detection of the proper band of tumour nucleotides on agarose gel is sensitive, but does not always have a high specificity due to the fact that false positives are sometimes obtained as a result of the weak expression in non-cancerous cells, such as mesothelial cells and lymphocytes (Kodera et al, 1998; Sakakura et al, 2001). The real-time quantitative RT-PCR is a more specific and quantitative method for the detection of tumour nucleotides by free cancer cells in peritoneal washes (Nakanishi et al, 2000; Osaka et al, 2004). The objective of this study was to clarify the clinical impact of the realtime quantitative RT-PCR-based identification of isolated tumour cells in the peritoneal lavage fluid of gastric carcinoma. 


\section{MATERIALS AND METHODS}

\section{Patients}

In this study, 124 patients with gastric cancer were enrolled. A laparotomy and preoperative peritoneal lavage were performed on all 124 patients who intended to undergo a gastrectomy in our department. During the operation, the abdominal cavity was thoroughly examined for tumour metastasis. When a potentially curative resection was considered possible, a gastrectomy with a D2 lymphadenectomy was performed. A palliative resection was performed for the patients who were not treated with a curative resection. A bypass operation was performed for patients who were unable to receive a gastrectomy because of extensive invasion to adjacent organs or extensive peritoneal dissemination. Five patients were excluded who died as a result of liver metastasis (three patients), lung metastasis (one patient), and bone metastasis (one patient). Glyceraldehyde-3-phosphate dehydrogenase (GAPDH) mRNA was undetectable in the samples of three patients. Next, the data from the remaining 116 patients were analysed. Of the 116 patients with resectable cancer, 80 underwent a potentially curative R0 resection, 29 were treated with a palliative resection, and the remaining seven patients were considered unresectable and underwent bypass operations. As negative controls, the peritoneal lavage specimens obtained from 10 of the patients with cholecystolithiasis for cholecystectomy were used. Informed consent to participate in this study was obtained from all of the patients before their surgery. The pathologic diagnoses and classifications were made according to the TNM staging system (Sobin, 2003) of the Union Internationale Contre le Cancer (UICC). After the surgical resection, all patients underwent a follow-up, with the median follow-up at analysis being 32 months for all patients. The follow-up programme of post-operative surveillance consisted of physical examination, blood chemistry including CEA, computed tomography, and ultrasound performed every 3 months to diagnose recurrent diseases.

\section{Peritoneal lavage sample}

Just after laparotomy, $100 \mathrm{ml}$ of normal saline was poured into the Douglas' pouch and then was left in the subphrenic space, and then the peritoneal lavage fluid was collected from the cavity before a surgical resection. Half of the peritoneal lavage fluid was examined through conventional cytological methods with Papanicolaou staining, and for the remaining half, the free cancer cells in the abdominal cavity were detected by means of a molecular diagnosis, as described below.

\section{RNA extraction}

The peritoneal lavage fluid was centrifuged at 2000 r.p.m. for 10 min to collect the intact cells and then dissolved in a TRIZOL Reagent (Gibco, Gaithersburg, MD, USA). The mixture and $0.5 \mathrm{ml}$ of chloroform in a $1.5 \mathrm{ml}$ tube was centrifuged at 12000 r.p.m. for $15 \mathrm{~min}$. Next, the supernatant was transferred to a fresh tube, and $0.2 \mathrm{ml}$ propanol was added. The RNA was precipitated after centrifugation at 12000 r.p.m. for $10 \mathrm{~min}$, washed with $75 \%$ ethanol, and diluted with DEPC-treated water. The purified RNA was then quantified and assessed for purity by UV spectrophotometry.

\section{Reverse transcriptase-polymerase chain reaction}

Complementary DNA (cDNA) was prepared from each sample using oligo- $(\mathrm{dT})_{15}$ primer and M-MLV Reverse Transcriptase (Life Technologies, Rockville, MD, USA). RT reaction was performed at $37^{\circ} \mathrm{C}$ for $50 \mathrm{~min}$, followed by heating at $70^{\circ} \mathrm{C}$ for $10 \mathrm{~min}$. PCR amplification was performed using the following primer sequences, For cytokeratin20 (CK20): forward 5'-CTCTCCTCA AAAAGGAGCATCAG- ${ }^{\prime}$; reverse $5^{\prime}$-CAACCTCCACATTGACAGT GTTG-3'; Taqman probe FAM-CAGATGCTTGTGTAGGCCATC GACTTCCT-TAMRA. For carcinoembryonic antigen (CEA): forward 5'-CAATAGGACCACAGTCACGACGAT-3', reverse 5'-GGTT GGAGTTGTTGCTGGTGAT-3'; Taqman probe FAM-ACAGTC TATGCAGAGCCACCCAAACCCTT-TAMRA. For GAPDH: forward $5^{\prime}$-GAAGGTGAAGGTCGGAGTC- ${ }^{\prime}$, reverse $5^{\prime}$-GAAGATGGTGAT GGGATTTC-3', Taqman probe VIC-CAAGCTTCCCGTTCTCAG CC-TAMRA. Real-time quantitative RT-PCR was carried out using the ABI PRISM 7700 Sequence Detection system (Applied Biosystems, Foster City, CA, USA) per the manufacturer's protocol. The total volume of the PCR was $50 \mu \mathrm{l}$, containing $2 \mu \mathrm{l}$ of cDNA template, $25 \mu \mathrm{l}$ TaqMan Universal PCR Master Mix (Applied Biosystems), $0.1 \mu \mathrm{M}$ probe, and $0.3 \mu \mathrm{M}$ of each primer. The PCR conditions were as follows: after incubation at $50^{\circ} \mathrm{C}$ for $2 \mathrm{~min}$ and denaturing at $95^{\circ} \mathrm{C}$ for $10 \mathrm{~min}, 40$ cycles of $15 \mathrm{~s}$ at $95^{\circ} \mathrm{C}$, and $60 \mathrm{~s}$ at $60^{\circ} \mathrm{C}$. The mRNA level of each gene was normalised by the internal control GAPDH.

\section{Standard curve}

The gastric cancer cell line, OCUM-2M (Yashiro et al, 1995), was used for the construction of a standard curve of CEA and CK2O expression. The cDNA from $1 \mu \mathrm{g}$ of RNA from the OCUM-2M cells was diluted with normal monocytes at various ratios. The PCR cycling conditions according to the manufacturer's protocol were 40 cycles of $15 \mathrm{~s}$ at $95^{\circ} \mathrm{C}$ and $60 \mathrm{~s}$ at $60^{\circ} \mathrm{C}$. The threshold cycle $C_{\mathrm{t}}$ represents the fractional cycle number at which a significant increase above the baseline signal was first detected. The log starting copy number is plotted against the threshold cycle $C_{\mathrm{t}}$. The standard curves for $C E A, C K 20$, and GAPDH were then constructed. According to the standard curve, the CEA and CK20 mRNA levels were calculated.

\section{Statistical analysis}

We used the $\chi^{2}$ test, Fisher's exact test, or the Mann-Whitney $U$-test to determine the significance of the differences between the covariates. The survival durations were calculated using the Kaplan-Meier method and were analysed by the log-rank test to compare the cumulative survival durations in the patient groups. The survival curve was calculated from the date of surgery. The Cox proportional hazards model was used to compute the univariate and multivariate hazards ratios for the study parameters. For all of the tests, a $P$-value of less than 0.05 was considered to be statistically significant. The SPSS software program (SPSS Japan, Tokyo, Japan) was used for the analyses.

\section{RESULTS}

\section{Determination of cutoff values}

Figure 1 shows the CEA/GAPDH mRNA ratios and the CK20/ GAPDH mRNA ratios according to the depth of the tumour invasion. Each cutoff value was determined as the mean plus 2 s.d. based on the quantified values of the control and the T1 samples. The cutoff value of the CEA/GAPDH (Figure 1A) and CK20/GAPDH (Figure 1B) levels were $2.490 \times 10^{-2}$ and $6.726 \times 10^{-3}$, respectively. When the CEA or CK20 mRNA/GAPDH mRNA level of the sample was above the cutoff value, the mRNA expression was considered positive, and the sample was determined to be PCR-positive.

\section{Correlation between clinicopathological factors and CEA} and/or CK20 expression in the peritoneal lavage fluid

All 116 patients were subjected to both a CEA and/or CK20 examination and a cytological examination. All of the peritoneal 
Cytology negative/dead $\mathrm{O}$ Cytology negative/alive

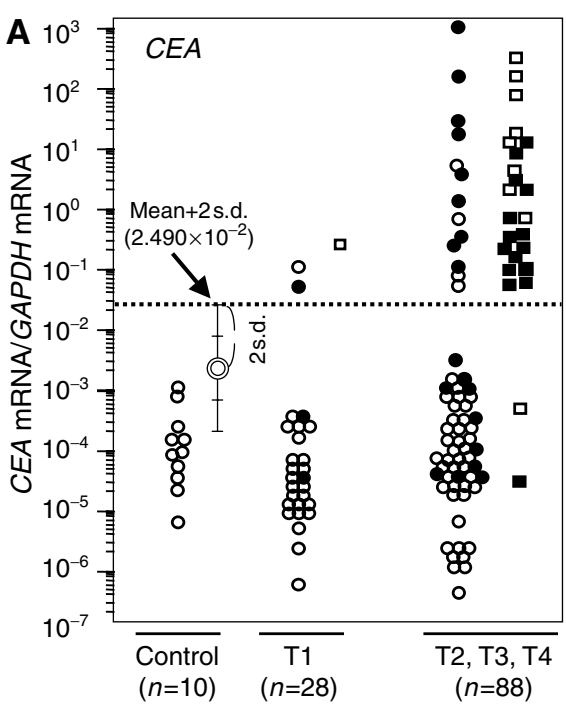

- Cytology positive/dead $\square$ Cytology positive/alive

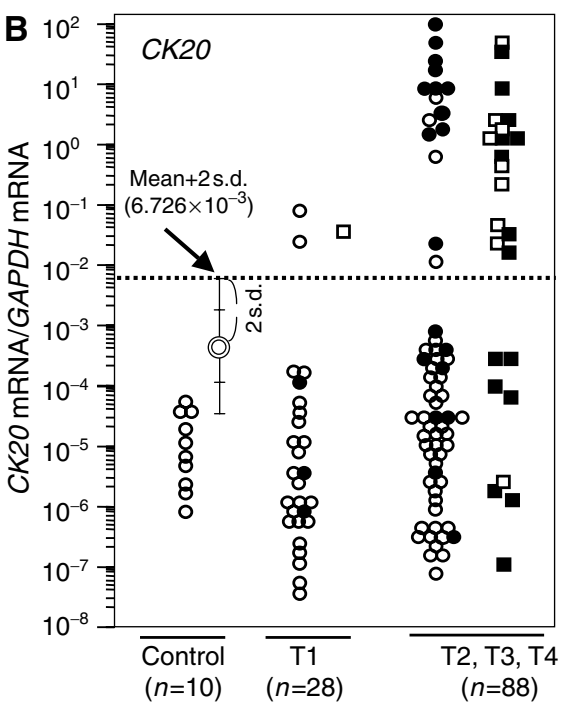

Figure I Expression levels of CK20 and CEA mRNA. CEA/GAPDH mRNA ratios and CK20/GAPDH mRNA ratios were shown according to depth of tumour invasion. The CEA mRNA and CK20 mRNA expression of the peritoneal lavage fluid of the control samples $(n=10)$, TI $(n=28)$, T2 $(n=23)$, T3 $(n=52)$, and T4 $(n=13)$, were quantified by RT -PCR. The CEA/GAPDH mRNA ratios and CK20/GAPDH mRNA ratios were plotted according to T stage of TNM classification. Each cutoff value was determined based on the mean plus 2 s.d. of the CEA/GAPDH mRNA ratios and CK20/GAPDH mRNA ratios level in the peritoneal lavage fluid of the control and TI samples. (A) The cutoff value of CEA/GAPDH was $2.490 \times 10^{-2}$. CEA was positive in 3 (I I\%) of the 28 patients with TI cancer and in 35 (40\%) of the 88 patients with T2, T3, or T4 cancer. (B) The cutoff value of CK20/GAPDH was 6.726 $\times 10^{-3}$. CK20 was positive in 3 ( 1 I\%) of the 28 patients with TI cancer, and 31 (35\%) of the 88 patients with T2, T3, or T4 cancer were CK20-positive. Sixty-four (73\%) of the 88 patients with T2, T3, or T4 cancer were cytology-negative, and 19 (30\%) of the 64 cytology-negative patients with T2, T3, or T4 cancer died due to peritoneal recurrence. In these 19 patients, CEA or CK20 was positive in 9 and II, respectively. The open or closed circles show the cytology-negative patients. The open or closed squares show the cytology-positive patients. The closed circle and closed square show patients who died by peritoneal recurrence Owing to the TNM staging system of the Union Internationale Contre le Cancer.

lavages from the control $(n=10)$ were negative for the quantitative RT - PCR of CEA and/or CK20 expression. CEA was positive in three $(11 \%)$ of the 28 patients with T1 cancer and in $35(40 \%)$ of the 88 patients with T2, T3, or T4 cancer (Figure 1A). CK20 was positive in three $(11 \%)$ of the 28 patients with $\mathrm{T} 1$ cancer, and 31 (35\%) of the 88 patients with T2, T3, or T4 cancer were CK20positive (Figure 1B). Sixty-four (73\%) of the 88 patients with T2, T3, or T4 cancer were cytology-negative, and 19 (30\%) of the 64 cytology-negative patients with $\mathrm{T} 2, \mathrm{~T} 3$, or $\mathrm{T} 4$ cancer died as a result of peritoneal recurrence. In these 19 patients, CEA or CK20 was positive in 9 and 11 , respectively (Figure 1). Table 1 summarises the correlation between the CEA and/or CK-20 expression of the peritoneal lavage fluid and the clinicopathological parameters. The molecular diagnosis significantly correlated with the $\mathrm{T}$ stage as the depth of tumour invasion $(P<0.001)$, peritoneal dissemination at operation $(P<0.001)$, cytology $(P<0.001)$, stage $(P<0.001)$, and lymph node disease $(P<0.001)$. In contrast, there was no statistically significant association between CEA and/or CK20 and hepatic metastasis at operation, tumour differentiation, venous invasion, or lymphatic invasion.

\section{Recurrent peritoneal metastasis}

Peritoneal recurrence was analysed in 116 patients. Table 2 summarises the correlation between peritoneal recurrence in these 116 cases and the results of the peritoneal lavage assays. Thirtyeight $(33 \%)$ of the 116 patients were positive for CEA mRNA and $34(29 \%)$ of the 116 patients were positive for $C K-20$ mRNA. Fortysix $(40 \%)$ patients were positive for either marker and were thus determined to be PCR-positive. The sensitivities and specificities were calculated based on the diagnosis of peritoneal metastases during the postoperative surveillance period. Death by recurrent peritoneal metastasis was found in $37(32 \%)$ of the 116 patients.
CEA or CK20 mRNA levels are helpful for the prediction of peritoneal recurrence with a sensitivity of 72.7 or $54.6 \%$, and a specificity of 82.7 or $80.3 \%$, respectively (Table 2 ). In Figure 1, the closed circle and square show patients who died by peritoneal recurrence. Peritoneal recurrence was frequently found in 34 of the 88 advanced gastric cancer (T2, T3, and T4 categories) patients, while it was found in only three of the 28 early gastric cancer (T1 category) patients. Meanwhile, the combination of $C E A$ and/or CK20 mRNA levels had a sensitivity of $86.4 \%$ and a specificity of $81.5 \%$.

\section{Survival}

The prognosis of all 116 patients with PCR-positive tumours was significantly $(P<0.001)$ worse than those with $P C R$-negative tumours (Figure 2A). Moreover, in the 80 patients with a curative R0 resection, the prognosis of the PCR-positive patients $(n=15)$ was significantly $(P<0.001)$ worse than those 65 patients who were PCR-negative (Figure 2B). In addition, we analysed the prognostic significance of the CEA and/or CK20 expression in the four subgroups, T1, T2, T3, and T4 (Figure 3 ). The prognosis of the patients with PCR-positive cancer was significantly poorer than those with PCR-negative cancer in the T3 $(P<0.0001$; Figure $3 \mathrm{~A})$ and T4 $(P=0.048$; Figure $3 \mathrm{~B})$ subgroups, while no significant difference in prognosis was found between the CEA and/or CK20 expression in the $\mathrm{T} 1$ and $\mathrm{T} 2$ subgroups (data not shown). In the clinical stage, the prognosis of the PCR-positive cancer was significantly poorer than the PCR-negative cancer in stage III $(P=0.0004$; Figure $3 C)$ and stage IV $(P=0.035$; Figure $3 \mathrm{D})$, while no significant difference in prognosis was found between the $C E A$ and/or CK20 expression in stages I and II (data not shown).

We evaluated prognostic markers in 80 patients of curative R0 resection. According to a univariate analysis (Table 3), the 
Table I Relationship between the RT-PCR results, cytology and clinicopathological findings at operation in 116 patients with gastric cancer

\begin{tabular}{|c|c|c|c|}
\hline \multirow[b]{2}{*}{$\begin{array}{l}\text { Clinicopathological } \\
\text { findings }\end{array}$} & \multicolumn{2}{|c|}{ RT-PCR (CEA/CK20) } & \multirow[b]{2}{*}{$P$-value } \\
\hline & $\begin{array}{c}\text { Positive } \\
n=46\end{array}$ & $\begin{array}{c}\text { Negative } \\
n=70\end{array}$ & \\
\hline \multicolumn{4}{|l|}{ Tumour depth ${ }^{\mathrm{a}}$} \\
\hline $\mathrm{Tl}$ or $\mathrm{T} 2$ & 7 & 44 & $<0.001$ \\
\hline $\mathrm{T} 3$ or $\mathrm{T} 4$ & 39 & 26 & \\
\hline \multicolumn{4}{|l|}{ Peritoneal metastasis } \\
\hline Positive & 12 & I & $<0.001$ \\
\hline Negative & 34 & 69 & \\
\hline \multicolumn{4}{|l|}{ Cytology } \\
\hline Positive & 25 & 2 & $<0.001$ \\
\hline Negative & 21 & 68 & \\
\hline \multicolumn{4}{|l|}{ Stage } \\
\hline | or || & 5 & 47 & $<0.001$ \\
\hline III or IV & 41 & 23 & \\
\hline \multicolumn{4}{|l|}{ LN metastasis } \\
\hline Positive & 40 & 36 & $<0.001$ \\
\hline Negative & 6 & 34 & \\
\hline \multicolumn{4}{|l|}{ Histological type } \\
\hline Intestinal type & 14 & 33 & 0.073 \\
\hline Diffuse type & 32 & 37 & \\
\hline \multicolumn{4}{|l|}{ Lymphatic invasion } \\
\hline Positive & 34 & 46 & 0.350 \\
\hline Negative & 12 & 24 & \\
\hline \multicolumn{4}{|l|}{ Venous invasion } \\
\hline Positive & 11 & 14 & 0.616 \\
\hline Negative & 35 & 56 & \\
\hline \multicolumn{4}{|l|}{ Hepatic metastasis } \\
\hline Positive & 5 & 2 & 0.076 \\
\hline Negative & 41 & 68 & \\
\hline
\end{tabular}

${ }^{a} \mathrm{TI}$ : tumour invades mucosa or submucosa, T2: tumour invades the muscularis propria or the subserosa, T3: tumour penetrates the serosa and exposed to abdominal cavity without invading the adjacent structures, T4: tumour invades the adjacent structures. Significance level of difference was determined using Fisher's exact test or $\chi^{2}$ test.

Table 2 Relationship between peritoneal recurrence and CEA or CK20 mRNA expression

\begin{tabular}{|c|c|c|c|c|c|}
\hline RT-PCR & $\begin{array}{c}\text { Death } \\
(n=37)\end{array}$ & $\begin{array}{c}\text { Alive } \\
(n=79)\end{array}$ & $P$-value & $\begin{array}{c}\text { Sensitivity } \\
\text { (\%) }\end{array}$ & $\begin{array}{c}\text { Specificity } \\
\text { (\%) }\end{array}$ \\
\hline \multicolumn{6}{|l|}{ CEA } \\
\hline Positive $(n=38)$ & 24 & 14 & $<0.001$ & 64.9 & 82.3 \\
\hline Negative $(n=78)$ & 13 & 65 & & & \\
\hline \multicolumn{6}{|l|}{ CK 20} \\
\hline Positive $(n=34)$ & 19 & 15 & $<0.001$ & 51.4 & 81.0 \\
\hline Negative $(n=82)$ & 18 & 64 & & & \\
\hline \multicolumn{6}{|l|}{ CEA and/or CK20 } \\
\hline Positive $(n=46)$ & 30 & 16 & $<0.001$ & 81.1 & 79.7 \\
\hline Negative $(n=70)$ & 7 & 63 & & & \\
\hline
\end{tabular}

Sensitivity was defined as the positive rate for the CEA/GAPDH mRNA ratio or the CK20/GAPDH mRNA ratio with peritoneal washes of patients who developed recurrent peritoneal carcinomatosis. Specificity was defined as the negative rate for the CEA/GAPDH mRNA ratio or the CK20/GAPDH mRNA ratio in patients without any signs of peritoneal carcinomatosis.
RT - PCR (CEA and/or CK20), T stage, and stage were significantly correlated with patient survival. In a multivariate analysis (Table 4), the RT-PCR (CEA and/or CK20), and tumour depth were found to be independent prognostic factors.

\section{DISCUSSION}

In patients with a curative $\mathrm{R} 0$ resection, the prognosis of the patients with $P C R$-positive tumours was significantly worse than those with PCR-negative tumours. Regarding overall survival, a multivariate analysis showed that the current real-time quantitative RT-PCR technique using CEA and/or CK20 was an independent prognostic factor for the patients with a curative R0 resection. Moreover, the RT-PCR method was found to be useful in T3 or T4 gastric cancer in which peritoneal dissemination is the main cause of death after a surgical resection. These findings suggest that the RT-PCR detection of the CEA and/or CK20 transcripts in the peritoneal lavage specimens has a prognostic relevance in patients who are undergoing a curative resection for T3 and T4 gastric cancer. Most of the current chemotherapy regimens have failed to improve the survival of $\mathrm{T} 3$ and $\mathrm{T} 4$ gastric cancer patients (Martin et al, 2002; Tsuburaya et al, 2005). The RT - PCR assay of peritoneal lavage can be a reliable method for the selection of patients for therapeutic chemotherapy.

Many markers, including CEA, CK20, CK19, MAGE, and MMP-7, have previously been applied to detect micrometastases of gastric cancer (Okami et al, 2000; Yonemura et al, 2001; Kodera et al, 2002; Lin et al, 2002; Matsuda et al, 2004; Arigami et al, 2006; Horibe et al, 2007). Our preliminary study showed that the CK19 and MMP-7 mRNA were detected in the peritoneal lavage fluid from the control benign disease, and that the MAGE-1 and MAGE-3 mRNA were occasionally undetectable in the cytology-positive samples. Also, the CK19 mRNA was expressed in the normal control tissues, and the presence of the pseudogenes of CK19 reportedly limits its value. Therefore, CK19, MAGE, and MMP-7 were not used as a diagnostic marker for the detection of peritoneal micrometastasis in this study. In contrast, CEA has been reported to be a reliable target for the detection of disseminated gastric cancer cells, and is the most common marker for detecting micrometastasis with RT-PCR (Kodera et al, 1998; Nakanishi et al, 2000; Osaka et al, 2004). The quantitative RT - PCR method using multiple markers reportedly improved the sensitivity and specificity of the quantitative RT-PCR method (Guller et al, 2002; Timar et al, 2002; Osaka et al, 2004; Fujita et al, 2006). We therefore selected the combination of CEA and $C K-20$ as diagnostic markers for predicting micrometastasis in patients with gastric carcinoma in this study.

Some papers have reported the use of GAPDH mRNA as a quantity marker to possibly not be necessary (Kodera et al, 2002; Ito et al, 2005). However, GAPDH is considered to be necessary because a specific genetic marker for gastric cancer has not yet been found. We used the $C E A / G A P D H$ ratio or $C K 20 / G A P D H$ ratio for a subsequent analysis in the present study. The cutoff value was determined based on the mean plus 2 s.d. of the samples of the benign disease and $\mathrm{T} 1$ gastric cancers, as well as those of the others (Osaka et al, 2004; Oyama et al, 2004). The PCR methods resulted in more false positives than other methods. The RT - PCR assay for $C E A$ frequently resulted in false negatives (Marutsuka et al, 2003) because the expression level of the CEA mRNA was heterogeneous in the gastric tumours which exhibited no expression of $C E A$ mRNA (Osaka et al, 2004), or due to the weak expression in the non-cancerous cells, such as the mesothelial cells. CK20 also has a relatively low specificity because of the frequent CK20 expression in not only the cancer cells but also in the normal epithelial cells. In our study, the sensitivity and specificity of the CEA or CK20 RT - PCR assay, which were useful for the prediction of peritoneal recurrence were 64.9 and $82.7 \%$ or 54.6 and $80.3 \%$, respectively. 

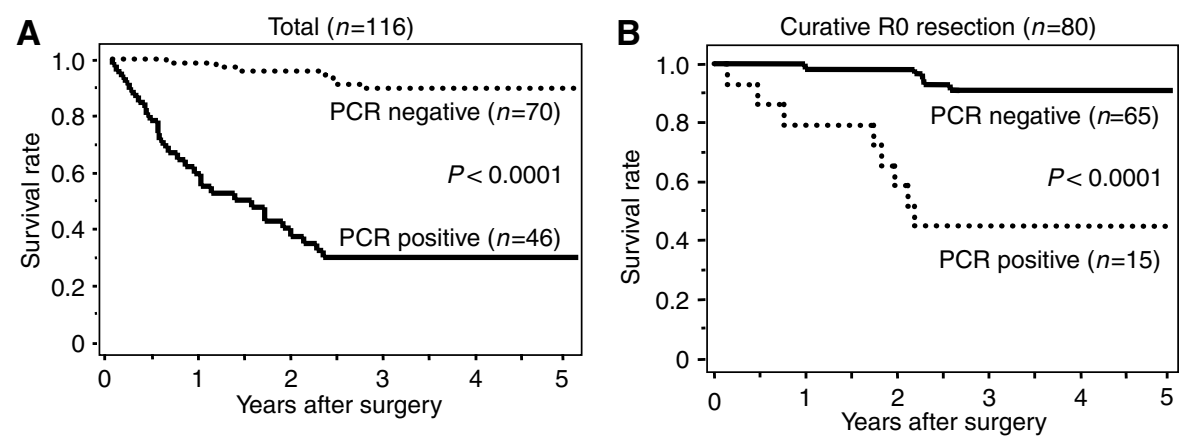

Figure 2 The overall survival of patients based on a PCR-based analysis. The survival curve shows the Kaplan-Meier overall survival curves in relation to the CEA and CK20 mRNA levels in the gastric carcinomas. (A) The prognosis of all I I 6 patients with PCR-positive tumours was significantly $(P<0.00$ I) worse than that of those with PCR-negative tumours. (B) In the 80 patients with a curative R0 resection, the prognosis of the PCR-positive patients $(n=15)$ was significantly $(P<0.00 \mathrm{I})$ worse than that of the 65 patients who were PCR-negative.

A

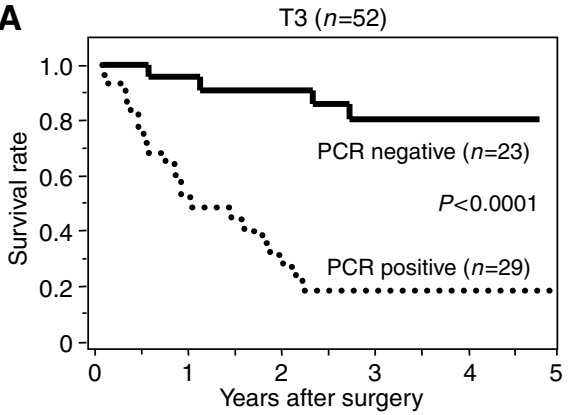

C

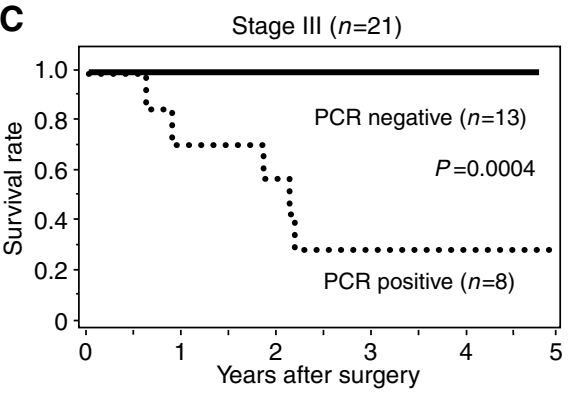

B

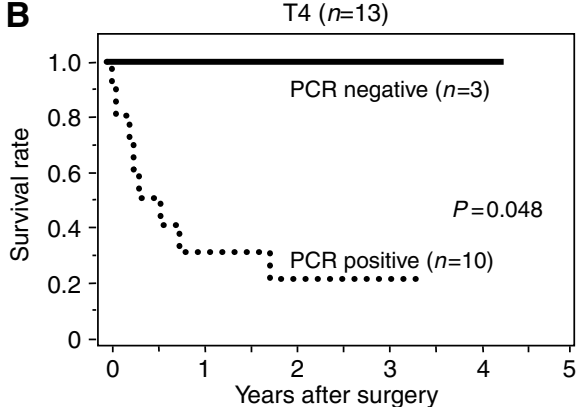

D

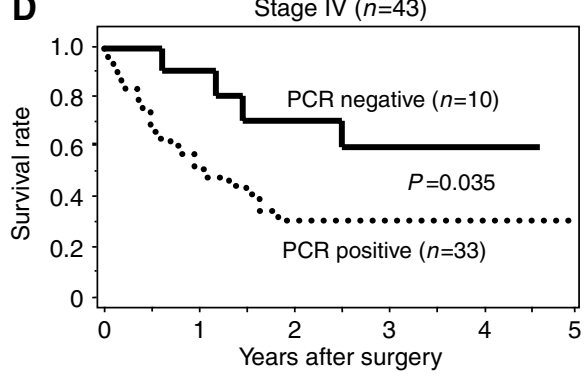

Figure 3 The overall survivals according to the status of T stage or clinical stage. The overall survivals of the subgroups of II 6 patients were subdivided according to the status of $\mathrm{T}$ stage or clinical stage. The PCR-positive patients had a significantly poor prognosis in comparison to those who were PCRnegative in the PT3 $(\mathbf{A})$ and PT4 stages $(\mathbf{B})$ The prognosis of the PCR-positive cancer was significantly poorer $(P=0.026)$ than that of the PCR-negative cancer in the stage III $(\mathbf{C})$ and stage IV (D) groups.

The combinations of the CEA and/or CK20 mRNA levels were 86.4 and $81.5 \%$, respectively. The sensitivity of each marker was low, but that in combination with CK20 and CEA increased $(81.5 \%)$ without any decrease in the specificity. When the cutoff value decreases, then each marker's sensitivity has been observed to increase. The cutoff value in this study is appropriate because both the sensitivity and specificity of multiple markers are high. On the other hand, 6 of 37 of both the cytology-negative and PCR-negative patients died as a result of peritoneal metastasis. The discovery of a novel specific marker for gastric cancer could be expected to create a higher accuracy for the detection of a few cancer cells in the peritoneal lavage fluid.

It has been reported that isolated tumour cells (ITC), which are single tumour cells or a small cell cluster (Sobin, 2003), do not always show morphological evidence of metastatic activity, such as peritoneal metastasis (Cserni et al, 2005). The DNA from necrotic cancer cells may be detectable by PCR method in the peritoneal cavity but they are nonviable and therefore their identification at the DNA level would thus be misleading concerning tumour progression. Our study showed that, in the cytology-negative patients, 11 of the 17 PCR-positive patients died due to recurrent peritoneal dissemination, and the prognosis of the PCR-positive patients was significantly $(P<0.0001)$ worse than that of the PCR-negative patients. mRNA is detectable in viable cells because RNA is unstable in necrotic cancer cells. These findings suggest that the micrometastatic cells identified at the RNA level by real-time quantitative RT - PCR assay are considered to be viable for developing tumour progression for peritoneal metastasis.

The metastatic processes that are responsible for peritoneal dissemination remain controversial. Tumour cells originating in the abdomen can disseminate to the mesentery in three major 
Table 3 Univariate analysis with respect to overall survival in 80 patients of curative $\mathrm{RO}$ resection

\begin{tabular}{lccc}
\hline Parameter & Risk ratio & $\begin{array}{c}\mathbf{9 5 \%} \text { confidence } \\
\text { interval }\end{array}$ & P-value \\
\hline $\begin{array}{l}\text { RT_PCR(CEA and/or CK20) } \\
\quad \text { Negative vs positive }\end{array}$ & 9.2 & $3.0-28.5$ & $<0.001$ \\
$\begin{array}{l}\text { Tumour depth } \\
\text { TI/T2 vs T3/T4 }\end{array}$ & 11.1 & $2.4-50.1$ & 0.02 \\
$\begin{array}{l}\text { Stage } \\
\text { I/2 vs 3 }\end{array}$ & 5.8 & $1.8-18.8$ & 0.004 \\
$\begin{array}{l}\text { Lymph node metastasis } \\
\text { Negative vs positive }\end{array}$ & 1.9 & $0.6-5.7$ & 0.28 \\
$\begin{array}{l}\text { Lymphatic invasion } \\
\text { Negative vs positive }\end{array}$ & 3.1 & $0.68-13.9$ & 0.144 \\
$\begin{array}{l}\text { Venous invasion } \\
\text { Negative vs positive }\end{array}$ & 2.3 & $0.72-7.6$ & 0.160 \\
$\begin{array}{l}\text { Histological type } \\
\text { Intestinal type vs diffuse type }\end{array}$ & 0.872 & $0.29-2.6$ & 0.805 \\
\hline
\end{tabular}

ways: extension via the mesenteric lymphatics, embolic haematogenous spread, and intraperitoneal seeding (Meyers et al, 1987; Sheth et al, 2003; Tendo et al, 2006). In this study, the CEA and/or CK20 examination significantly correlated with the $\mathrm{T}$ stage as depth of tumour invasion $(P<0.001)$, peritoneal dissemination $(P<0.001)$, whereas there was no statistically significant association with venous invasion or lymphatic invasion. These findings suggest that peritoneal dissemination may arise from free cancer cells into the peritoneal cavity exfoliated mainly from the serosal surface of the stomach penetrated by the primary tumour.

In conclusion, a real-time quantitative RT - PCR analysis of the CEA and/or CK20 transcripts in the peritoneal lavage fluid is thus considered to be useful for predicting the peritoneal recurrence in patients who are undergoing a curative resection for gastric cancer.

\section{REFERENCES}

Abe S, Yoshimura H, Tabara H, Tachibana M, Monden N, Nakamura T, Nagaoka S (1995) Curative resection of gastric cancer: limitation of peritoneal lavage cytology in predicting the outcome. J Surg Oncol 59: $226-229$

Arigami T, Natsugoe S, Uenosono Y, Mataki Y, Ehi K, Higashi H, Arima H, Yanagida S, Ishigami S, Hokita S, Aikou T (2006) Evaluation of sentinel node concept in gastric cancer based on lymph node micrometastasis determined by reverse transcription-polymerase chain reaction. Ann Surg 243: $341-347$

Baba H, Korenaga D, Okamura T, Saito A, Sugimachi K (1989) Prognostic factors in gastric cancer with serosal invasion. Univariate and multivariate analyses. Arch Surg 124: $1061-1064$

Boku T, Nakane Y, Minoura T, Takada H, Yamamura M, Hioki K, Yamamoto M (1990) Prognostic significance of serosal invasion and free intraperitoneal cancer cells in gastric cancer. Br J Surg 77: 436-439

Cserni G, Bianchi S, Boecker W, Decker T, Lacerda M, Rank F, Wells CA (2005) Improving the reproducibility of diagnosing micrometastases and isolated tumor cells. Cancer 103: $358-367$

de Manzoni G, Verlato G, Di Leo A, Tomezzoli A, Pedrazzani C, Pasini F, Piubello Q, Cordiano C (2006) Peritoneal cytology does not increase the prognostic information provided by TNM in gastric cancer. World J Surg 30: $579-584$

Fujita Y, Terashima M, Hoshino Y, Ohtani S, Kashimura S, Kanzaki N, Osuka F, Kogure M, Gotoh M (2006) Detection of cancer cells disseminated in bone marrow using real-time quantitative RT-PCR of
Table 4 A multivariate analysis regarding the overall survival in 80 patients of curative $\mathrm{R} 0$ resection

\begin{tabular}{lccc}
\hline Parameter & Risk ratio & $\begin{array}{c}\mathbf{9 5 \%} \text { confidence } \\
\text { interval }\end{array}$ & P-value \\
\hline $\begin{array}{l}\text { RT-PCR(CEA and/or CK20) } \\
\text { Negative vs positive }\end{array}$ & 9.9 & $2.3-43.0$ & 0.002 \\
$\begin{array}{l}\text { Tumour depth } \\
\text { TI/T2 vs. T3/T4 }\end{array}$ & 14.1 & $1.7-116.9$ & 0.014 \\
$\begin{array}{l}\text { Stage } \\
\text { I/2 vs 3 }\end{array}$ & 3.1 & $0.16-62.1$ & 0.458 \\
$\begin{array}{l}\text { Lymph node metastasis } \\
\text { Negative vs positive }\end{array}$ & & & \\
$\begin{array}{l}\text { Lymphatic invasion } \\
\text { Negative vs positive }\end{array}$ & 0.2 & $0.018-2.2$ & 0.19 \\
$\begin{array}{l}\text { Venous invasion } \\
\text { Negative vs positive }\end{array}$ & 0.49 & $0.073-3.28$ & 0.463 \\
$\begin{array}{l}\text { Histological type } \\
\text { Intestinal type vs diffuse type }\end{array}$ & & & 0.818 \\
\hline & 1.2 & $0.24-6.0$ & 0.11 \\
\hline
\end{tabular}

The RT-PCR assay of peritoneal lavage might therefore be a reliable method for the selection of patients who should undergo therapeutic chemotherapy.

\section{ACKNOWLEDGEMENTS}

This study was supported in part by a Grant-in-Aid for Scientific Research 18591475, 18390369, 13671329, and 13470260 from the Ministry of Education, Science, Sports, Culture, and Technology of Japan, by a Grant-in-Aid for the Osaka City University Medical Research Foundation, and by a Grant-in-Aid for the Osaka Medical Research Foundation for Incurable Diseases.

CEA, CK19, and CK20 mRNA in patients with gastric cancer. Gastric Cancer 9: $308-314$

Guller U, Zajac P, Schnider A, Bosch B, Vorburger S, Zuber M, Spagnoli GC, Oertli D, Maurer R, Metzger U, Harder F, Heberer M, Marti WR (2002) Disseminated single tumor cells as detected by real-time quantitative polymerase chain reaction represent a prognostic factor in patients undergoing surgery for colorectal cancer. Ann Surg 236: 768-775; discussion $775-776$

Horibe D, Ochiai T, Shimada H, Tomonaga T, Nomura F, Gun M, Tanizawa $\mathrm{T}$, Hayashi $\mathrm{H}$ (2007) Rapid detection of metastasis of gastric cancer using reverse transcription loop-mediated isothermal amplification. Int J Cancer 120: 1063 - 1069

Ito S, Nakanishi H, Kodera Y, Mochizuki Y, Tatematsu M, Yamamura Y (2005) Prospective validation of quantitative CEA mRNA detection in peritoneal washes in gastric carcinoma patients. Br J Cancer 93: 986-992

Kodera Y, Nakanishi H, Ito S, Yamamura Y, Kanemitsu Y, Shimizu Y, Hirai T, Yasui K, Kato T, Tatematsu M (2002) Quantitative detection of disseminated free cancer cells in peritoneal washes with real-time reverse transcriptase-polymerase chain reaction: a sensitive predictor of outcome for patients with gastric carcinoma. Ann Surg 235: 499-506

Kodera Y, Nakanishi H, Yamamura Y, Shimizu Y, Torii A, Hirai T, Yasui K, Morimoto T, Kato T, Kito T, Tatematsu M (1998) Prognostic value and clinical implications of disseminated cancer cells in the peritoneal cavity detected by reverse transcriptase-polymerase chain reaction and cytology. Int J Cancer 79: 429-433 
Lin JC, Chen KY, Wang WY, Jan JS, Liang WM, Wei YH (2002) Evaluation of cytokeratin-19 mRNA as a tumor marker in the peripheral blood of nasopharyngeal carcinoma patients receiving concurrent chemoradiotherapy. Int J Cancer 97: 548-553.

Martin II RC, Jaques DP, Brennan MF, Karpeh M (2002) Extended local resection for advanced gastric cancer: increased survival versus increased morbidity. Ann Surg 236: $159-165$

Marutsuka T, Shimada S, Shiomori K, Hayashi N, Yagi Y, Yamane T, Ogawa M (2003) Mechanisms of peritoneal metastasis after operation for nonserosa-invasive gastric carcinoma: an ultrarapid detection system for intraperitoneal free cancer cells and a prophylactic strategy for peritoneal metastasis. Clin Cancer Res 9: 678-685

Matsuda J, Kitagawa Y, Fujii H, Mukai M, Dan K, Kubota T, Watanabe M, Ozawa S, Otani Y, Hasegawa H, Shimizu Y, Kumai K, Kubo A, Kitajima M (2004) Significance of metastasis detected by molecular techniques in sentinel nodes of patients with gastrointestinal cancer. Ann Surg Oncol 11: 250S-254S

Meyers MA, Oliphant M, Berne AS, Feldberg MA (1987) The peritoneal ligaments and mesenteries: pathways of intraabdominal spread of disease. Radiology 163: 593-604

Nakanishi H, Kodera Y, Yamamura Y, Ito S, Kato T, Ezaki T, Tatematsu M (2000) Rapid quantitative detection of carcinoembryonic antigenexpressing free tumor cells in the peritoneal cavity of gastriccancer patients with real-time RT-PCR on the lightcycler. Int $J$ Cancer 89: $411-417$

Okami J, Dohno K, Sakon M, Iwao K, Yamada T, Yamamoto H, Fujiwara Y, Nagano H, Umeshita K, Matsuura N, Nakamori S, Monden M (2000) Genetic detection for micrometastasis in lymph node of biliary tract carcinoma. Clin Cancer Res 6: 2326-2332

Osaka H, Yashiro M, Sawada T, Katsuragi K, Hirakawa K (2004) Is a lymph node detected by the dye-guided method a true sentinel node in gastric cancer? Clin Cancer Res 10: 6912-6918

Oyama K, Terashima M, Takagane A, Maesawa C (2004) Prognostic significance of peritoneal minimal residual disease in gastric cancer detected by reverse transcription-polymerase chain reaction. $\mathrm{Br} J$ Surg 91: $435-443$

Sakakura C, Hagiwara A, Shirasu M, Yasuoka R, Fujita Y, Nakanishi M, Aragane H, Masuda K, Shimomura K, Abe T, Yamagishi H (2001) Polymerase chain reaction for detection of carcinoembryonic antigen- expressing tumor cells on milky spots of the greater omentum in gastric cancer patients: a pilot study. Int J Cancer 95: 286-289

Schofield K, D'Aquila T, Rimm DL (1997) The cell adhesion molecule, E-cadherin, distinguishes mesothelial cells from carcinoma cells in fluids. Cancer 81: $293-298$

Sheth S, Horton KM, Garland MR, Fishman EK (2003) Mesenteric neoplasms: CT appearances of primary and secondary tumors and differential diagnosis. Radiographics 23: 457-473; quiz 535-536

Singletary SE, Greene FL, Sobin LH (2003) Classification of isolated tumor cells: clarification of the 6th edition of the American Joint Committee on Cancer Staging Manual. Cancer 98: 2740-2741

Sobin LH (2003) TNM, sixth edition: new developments in general concepts and rules. Semin Surg Oncol 21: 19-22

Tendo M, Yashiro M, Nakazawa K, Yamada N, Sawada T, Ohira M, Hirakawa K (2006) A synergic inhibitory-effect of combination with selective cyclooxygenase- 2 inhibitor and S-1 on the peritoneal metastasis for scirrhous gastric cancer cells. Cancer Lett 244: 247-251

Timar J, Csuka O, Orosz Z, Jeney A, Kopper L (2001) Molecular pathology of tumor metastasis. I. Predictive pathology. Pathol Oncol Res 7: $217-230$

Timar J, Csuka O, Orosz Z, Jeney A, Kopper L (2002) Molecular pathology of tumor metastasis. II. Molecular staging and differential diagnosis. Pathol Oncol Res 8: 204-219

Tsuburaya A, Sakamoto J, Morita S, Kodera Y, Kobayashi M, Miyashita Y, Macdonald JS (2005) A randomized phase III trial of post-operative adjuvant oral fluoropyrimidine versus sequential paclitaxel/oral fluoropyrimidine; and UFT versus S1 for T3/T4 gastric carcinoma: the Stomach Cancer Adjuvant Multi-institutional Trial Group (Samit) Trial. Jpn J Clin Oncol 35: 672-675

Yashiro M, Chung YS, Nishimura S, Inoue T, Sowa M (1995) Establishment of two new scirrhous gastric cancer cell lines: analysis of factors associated with disseminated metastasis. Br J Cancer 72: 1200-1210

Yonemura Y, Fujimura T, Ninomiya I, Kim BS, Bandou E, Sawa T, Kinoshita K, Endo Y, Sugiyama K, Sasaki T (2001) Prediction of peritoneal micrometastasis by peritoneal lavaged cytology and reverse transcriptase-polymerase chain reaction for matrix metalloproteinase-7 mRNA. Clin Cancer Res 7: 1647 - 1653

Yoo CH, Noh SH, Shin DW, Choi SH, Min JS (2000) Recurrence following curative resection for gastric carcinoma. Br J Surg 87: 236-242 